\title{
Scheduling of Flexible Manufacturing System using Genetic Algorithm (Multiobjective): A Review
}

\author{
Navnikaa Rajan \\ CSE Dept. \\ IMS Engineering \\ College
}

\author{
Srishti Jaiswal \\ CSE Dept. \\ IMS Engineering \\ College
}

\author{
Tanya Kalsi \\ CSE Dept. \\ IMS Engineering \\ College
}

\author{
Vijai Singh \\ Assistant Professor \\ IMS Engineering \\ College
}

\begin{abstract}
A flexible, integrated, computer-controlled environment allows the system to react on occurrence of changes, whether predicted or unpredicted. Scheduling machines of varying capabilities in such an environment has always been a difficult task. This work reviews the various approaches applied to the scheduling problem in an FMS. Various genetic algorithm based approaches considering varied objectives and constraints have been studied and analysed to result in a comparative study. For achieving the desired performance in an FMS it is required that a good scheduling system, taking into account the system conditions should generate an optimal schedule at the right time. Genetic algorithm is capable of finding near to optimal solution in a short time although it doesn't guarantee to find an optimal solution.
\end{abstract}

\section{INTRODUCTION}

To sustain in todays competitive global market manufacturing organizations have to develop a manufacturing system that

\begin{abstract}
can fulfil the changing demands of customer for customised products. The system should be flexible, productive and should be able to meet the demands within time bounds at a reasonable cost. FMS belongs to a class halfway amidst job shop manufacturing system and batch manufacturing system. An FMS has an integrated and computer controlled configuration which is capable of automatically changing tools and parts. These machines are interconnected by automatic guided vehicles, pallets and storage buffers that have flexibility that allows modifying system behaviour on occurrence of changes whether predicted or unpredicted. It is modelled as a collection of workstations. The FMS should be designed to simultaneously manufacture different volumes of a varying variety of high quality products. The flexibility may be machine flexibility or routing flexibility. Machine flexibility refers to system's ability to produce new product types and change the sequence of operations executed on a part. Routing flexibility is the ability to absorb large scale changes such as in volume, capacity and capability.
\end{abstract}

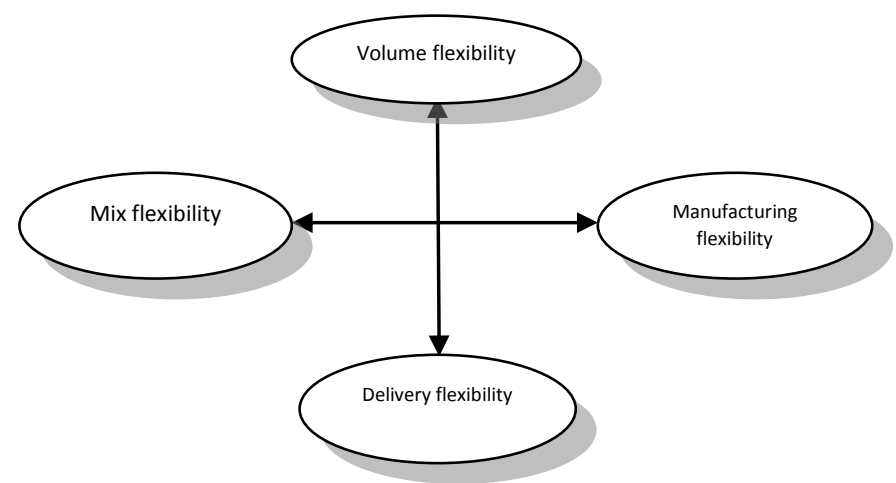

Fig 1:Types Of flexibilities

The arrangement of machines in an FMS is connected by a transport system. The components are automatically governed using local area network.

\section{Basic components of FMS}

FMS basically composes of the following three parts:

1. Workstations: A machine tool which is computer controlled is called a workstation. Machine centers,load/unload stations, assembly workstations, inspection stations, forging stations, sheet metal processing etc are a few examples of workstations.

2. Automated Storage stations and Material handling stations: The movement of work parts and sub assembly parts between different workstations is done mechanically which is referred to as automated material handling and storage system. The functions performed are: (i) Random movement of work parts between stations independently

(ii) Handling various work part configurations

(iii) Temporary storage

(iv)Loading and unloading of work parts for easy access

(v) Computer control compatibility

3. Computer controlled systems: The functioning of the stated components is co-ordinated by a controlling Computer System. Its functions are:

(i) Controlling work stations

(ii) Control instruction distribution to the work stations

(iii)Controlling production

(iv)Controlling traffic 
(v)Monitoring and work handling

(vi)Monitoring the performance of the system and reporting

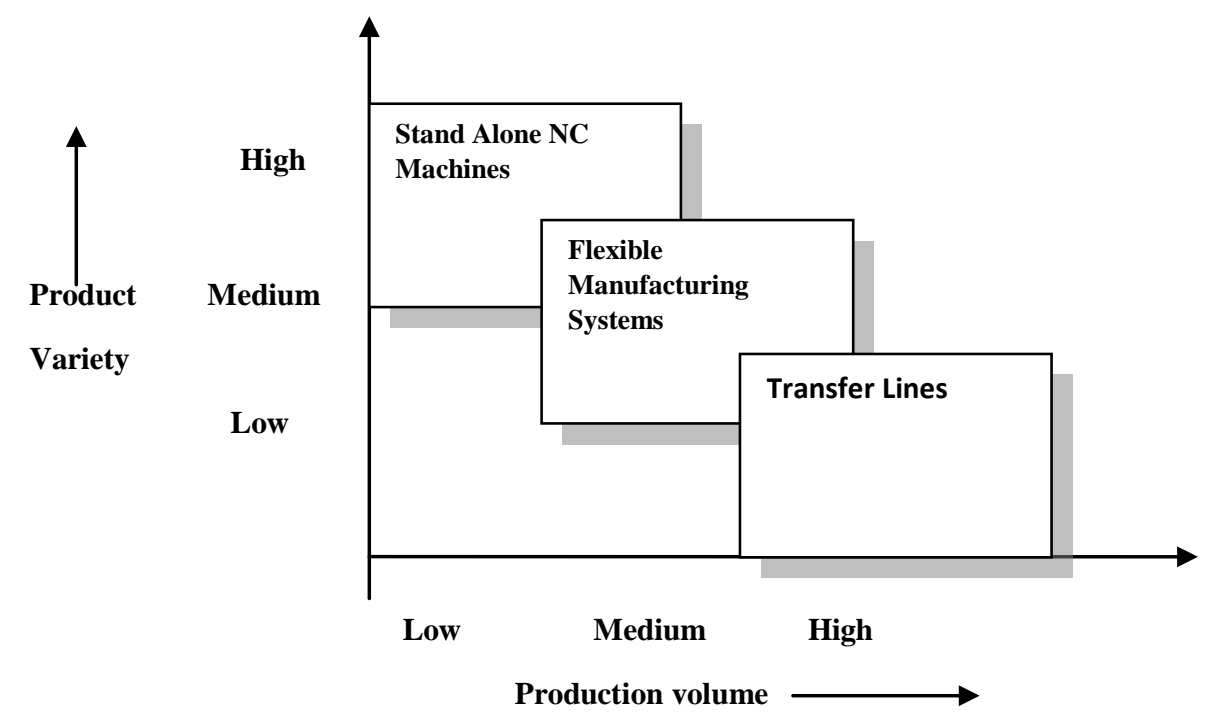

Fig 2: Application characteristics of FMS

Table 1.1 Different approaches to flexibility and their meanings

\begin{tabular}{|c|c|}
\hline Approach & Flexibility meaning \\
\hline $\begin{array}{l}\text { 2.Operational } \\
\text { 3.Customer } \\
\text { 4.Strategic } \\
\text { 5.Capacity }\end{array}$ & $\begin{array}{l}\text { - The capability of producing different parts without major retooling and changes } \\
\text { - } \\
\text { - } \text { p measure of how fast the company converts its process from making an old line of } \\
\text { - The ability to change a production schedule, to modify a part, or handling of multiple } \\
\text { parts } \\
\text { - The ability to efficiently produce highly customised products which are also unique } \\
\text { - The ability of exploiting various dimensions of delivery speed } \\
\text { - The ability of a company to offer a wide range and variety of products to its } \\
\text { customers } \\
\text { - The ability to quickly increase or decrease production levels or shifting the capacity } \\
\text { rapidly from one service or product to another service or product }\end{array}$ \\
\hline
\end{tabular}

Various approaches have been proposed for the scheduling problem of FMS including branch and bound, priority rules, simulated annealing, tabu search and genetic algorithm. Among these approaches the genetic algorithm approach with variations has been extensively applied for scheduling in an FMS.

Genetic algorithm by J.Holland is a randomised search and optimisation technique which is governed by the principles of evolution and natural genetics. It has been studied that it is difficult for the traditional optimisation techniques to approach the best solution. It is observed that genetic algorithms have better capability than the traditional scheduling methods.

\section{GENETIC ALGORITHM}

GAs is adaptive heuristic search algorithms based on the evolutionary ideas of natural selection and genetic. As such they represent an intelligent exploitation of a random search used to solve optimisation problems. They exploit historical information to direct the search into the region of better performance within the search space.

GA belongs to the class of evolutionary algorithms. John Holland based GA on the basic Darwinian Mechanism of "Survival of the fittest"[12].

Principle: The principle of GA is simple, it imitates genetics and natural selection by a computer approach. The parameters of the problem are coded most naturally as DNA.A set called population of these problems dependent parameter value vector is processed by GA.

They are more robust and hence better than the traditional algorithms. They do not break easily even if the inputs are varied slightly or in the presence of reasonable amount of noise.

Genetic algorithms are preferred over other approaches because of the following advantages 
- Genetic Algorithm works smoothly with numerical experimental or analytical functions and data.

- Well suited for parallel computing.

- Genetic Algorithm optimizes both variables efficiently, continuous or discrete.

- It doesn't requires any derivative information.

- It searches from a large sampling of the cost surface.

- It is capable of handling a large number of variables at the same time.

- It can optimize variables with highly complex cost surfaces.

- Gives a number of optimum solutions, not a single solution.

- It works on encoded variables

A GA typically consists of the following steps:

Step 1: Generate the initial population. Obtain the population size and the maximum number of iterations.

Step 2: Compute the fitness function for every member of the initial population.

Step 3: Compute the selection probability for every member of the initial population by calculating the ratio of fitness value of that initial population to the sum of the fitness values of all the individuals.

Step 4: Select two members (parents) to be used for reproduction based on selection probability.

Step 5: Apply crossover, mutation, and inversion to the parents to obtain the offspring. Generated offspring form the new generation.

If the size of the new population is equal to the initial population size, go to step 6 , else go to step 4 .

Step 6: If the current generation is equal to the maximum number of the generation then stop, else move to step 2 .

\subsection{Selection}

The process of choosing a pair of parents from the population for crossing in order to generate offspring is called crossover. The aim of selection is to choose fitter individuals so that the population has offspring having higher fitness value. Selection process randomly chooses chromosomes out of population based on the evaluation of their fitness function value. The higher fitness function value, more are the chances for the individual of being selected.

\subsection{Crossover}

The process of taking two parent solutions and generating a child is called crossover. The selection process enriches the population with fitter individuals. Crossover is a genetic operator used in genetic algorithm to vary the programming of a chromosome or chromosomes from one generation to the next. It is similar to reproduction in biological crossover, on which genetic algorithms is modelled.

\subsection{Mutation}

Mutation helps in avoiding the algorithm from being trapped in a local minimum. Mutation is responsible for recovering the lost genetic information. As crossover is responsible for exploiting the current population for finding better parents, mutation is designated for the exploration of the entire search space. It is an operator used for maintaining genetic diversity in the population. 


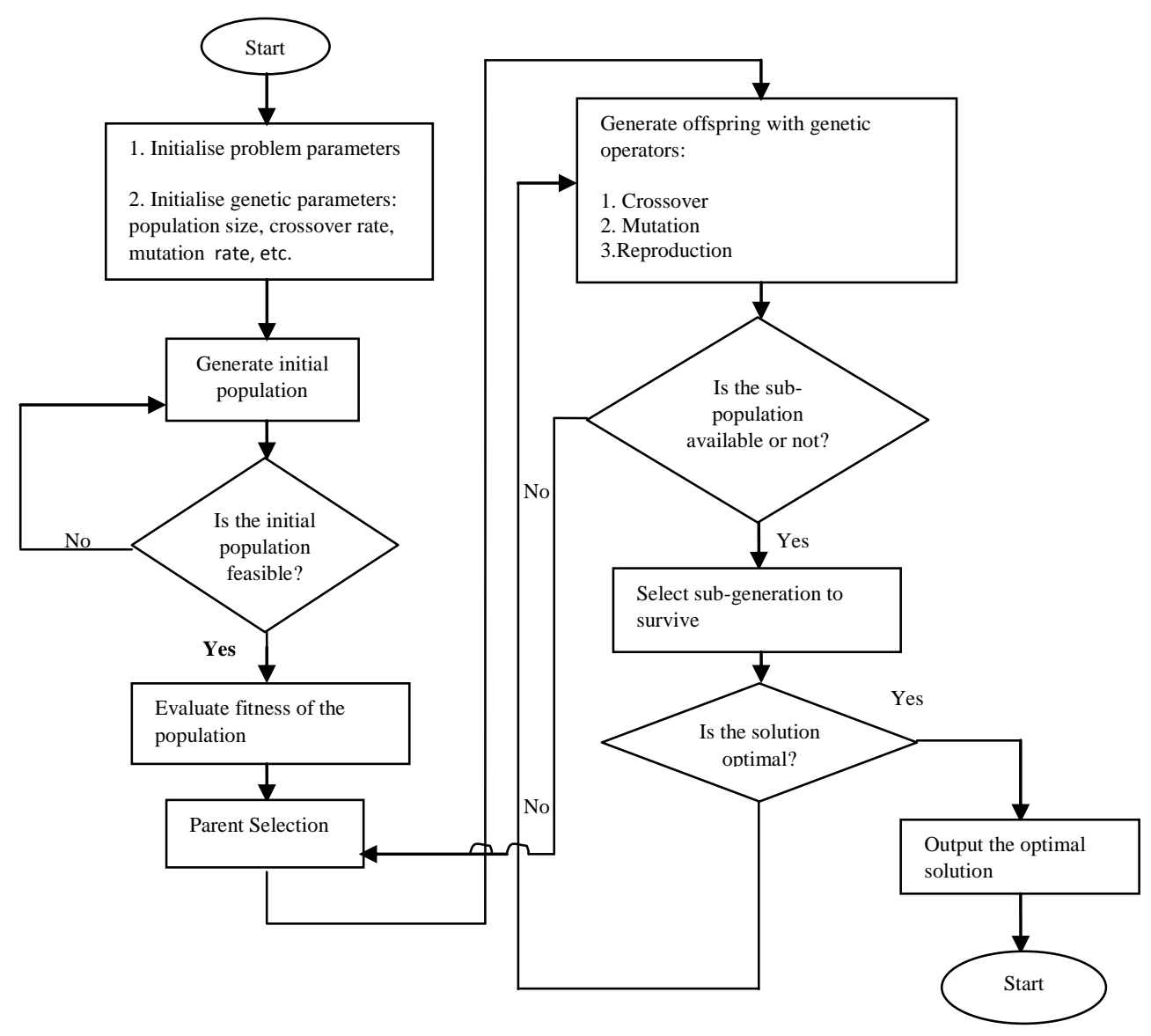

Fig 3: Steps of genetic algorithm

\section{LITERATURE SURVEY}

To gain a better insight into the FMS scheduling problem solution space a comparative review of the various algorithms, techniques and approaches has been done. The comparison was carried out while keeping in mind various parameters such as selection, mutation, crossover, fitness criteria and solution space. After in- depth analysis a conclusion can be inferred that there is a trade-off between optimality of solutions and computation time required. Since JSSP is a NP complete problem, there exists no specific algorithm which would give the optimal solution for all cases.

[9] Presents a new GA based Discrete Dynamic Programming approach for generating static schedules in a FMS environment. It adopts a sequence dependent schedule generation strategies where to generate feasible job sequences, GA is employed and a series of DDP are constructed to generate schedules. The author stated that DDP is capable of identifying locally optimised partial schedules. The proposed algorithm does not suffer from state explosion problem. The author concluded that the algorithm was successfully implemented for generation of schedules.

In [5] three objectives i.e. minimise make span, minimise maximal machine workload and minimum total workload are addressed and a hybrid genetic algorithm is proposed for a problem. They have used two vectors to represent the solution also two operators i.e. advance crossover and mutation operator are used to adapt special chromosome structure and varying characteristics of the problem. Authors have improved the genetic algorithm by variable neighbourhood descent in order to strengthen the search ability. The approach used involved two local search procedure; local search of moving one operation, local search of moving two operations. They have developed an efficient method for finding assignable time intervals for the deleted operations based on the earliest and latest event times. To unify the operation sequence in chromosome with the sequence in the decoded schedule or recorded procedure is used which facilitates genetic operators to pass from the good traits of the parents.

Liang Sun et al in their work [4] proposed a genetic algorithm with the penalty function for the FMS scheduling problem. For this, they used a clone selection based hyper mutation and a lifespan extended strategy. During a search process, an adaptive penalty function is decided so that the algorithm can search in both feasible and infeasible solution of the solution space. They conducted experiments on 23 benchmark and instances of the OR-Library. The proposed algorithm effectively exploits the capabilities of distributed and parallel computing of swarm intelligence approaches and effectively makes use of the famous scheme theorem and the building block hypothesis of Holland. The results indicate the successful incorporation of the proposed operators.

In paper [3] M. Heydar solved the FMS scheduling problem considering two objectives i.e. maximum completion time (make span) and maximum tardiness. This scheduling problem is stated belonging to the class of NP hard problems and hence no exact method is appropriate to solve the practical cases of scheduling problems. They proposed a hybrid genetic algorithm combined with four priority dispatching rules. The proposed approach resulted in performing well in efficiency and quality of solutions. 
In paper [6] Christian Bierwirth proposed a new representation technique mathematically known as permutation with repetition in order to sequence the operations of an FMS on a number of machines related to the technological machine order of jobs. A new crossover operator is designed with similar behaviour to the OrderCrossover for simple permutation schemes which reserves the initial scheme structure of permutations with repetitions. Together, the new representation and Generalisation of OX facilitates genetic search for scheduling problem. The author concluded that the representation demonstrates sustained performance on a platform of difficult benchmark problems and the algorithm attains a quality level of optimisation within the range of other GA approaches.

In this paper [7] Nidhish Mathew Nidhish, stated that the main characteristics of FMS is simultaneous execution of processes and sharing a finite set of resources. In this paper, a genetic algorithm based scheduling of FMS is presented with the objectives; minimising idle time of the machine and minimising the total penalty cost for not meeting the deadline. A software is also developed for getting optimal sequence of operation. The FMS under study has 16 CNC machine tools for processing 43 varieties of product. Various meta heuristic method are used for solving the same scheduling problems. Authors concluded the successful implementation of the procedure developed.

In this paper [8] a complex scheduling problem in flexible manufacturing system (FMS) has been addressed with a novel approach called knowledge based genetic algorithm (KBGA). It was stated that meta heuristics may be used for combinatorial decision making problems. This approach combines knowledge based which uses expert knowledge and genetic algorithm for searching optimal solution. The approach has been applied on four different stages of genetic algorithm. The authors tested KBGA on 10 different moderate size of data. It has been concluded that in the proposed algorithm the operators also used with knowledge based to reduce computational obstacles.

In [2] Vijai Singh et al stated that achieving high performance for an FMS require good scheduling system which makes a right decision at the right time considering the system conditions which is difficult using traditional optimising techniques. Author has made use of genetic algorithm with roulette wheel based selection process. They concluded that roulette wheel selection process is fast and easy to implement and GA based scheduling has considerable potential application to FMS.

Swati Singh et al in their work[1] stated job shop scheduling problem as one of the most difficult NP hard combinatorial optimisation problem. Hence, optimal schedule determination is considered difficult. Their paper focussed on the objective of generating a schedule, minimising total make span time using genetic algorithm. They concluded that JSSP may have made a schedule depending upon the number of jobs and machine. Genetic algorithm is preferred over traditional scheduling methods

\section{RESULT}

The comparative analysis of the work studied is presented in the table below:

Table 1.2:Comparative summarization of the reviewed papers

\begin{tabular}{|c|c|c|c|c|c|}
\hline & Objective & Selection & Crossover & Mutation & Future work \\
\hline $\begin{array}{l}\text { JSSP with delay } \\
\text { constraints[1] }\end{array}$ & $\begin{array}{l}\text { Improving solution } \\
\text { to JSSP } \\
\text { problem(i.e. } \\
\text { minimising make } \\
\text { span) }\end{array}$ & Random & $\begin{array}{l}\text { Single point } \\
\text { crossover at point } \\
\text { ceil [p/2] } \\
\mathrm{P}=\text { no. of piece/job } \\
\mathrm{N}=\text { total jobs }\end{array}$ & $\begin{array}{l}\text { Transposition } \\
\text { Mutation } \\
\text { probability }=0.5\end{array}$ & $\begin{array}{l}\text { 1. Assumed no } \\
\text { breakdown. } \\
\text { 2. Considered jobs } \\
\text { atomic. } \\
\text { 3. Considered } \\
\text { transportation and } \\
\text { setup time constant. }\end{array}$ \\
\hline $\begin{array}{l}\text { FMS Scheduling } \\
\text { using Roulette } \\
\text { wheel selection[2] }\end{array}$ & $\begin{array}{l}\text { Minimising the } \\
\text { total make span } \\
\text { time }\end{array}$ & $\begin{array}{l}\text { Roulette wheel } \\
\text { selection }\end{array}$ & $\begin{array}{l}\text { Single point } \\
\text { crossover with } \\
\text { fixed crossover } \\
\text { probability in } \\
\text { range[1,L-1] }\end{array}$ & Flipping & $\begin{array}{l}\text { 1. Assumed no } \\
\text { breakdown. } \\
\text { 2.Transportation } \\
\text { and setup time } \\
\text { constant }\end{array}$ \\
\hline $\begin{array}{l}\text { Multiobjective } \\
\text { Hybrid GA } \\
\text { method[3] }\end{array}$ & $\begin{array}{l}\text { Minimise make } \\
\text { span and maximise } \\
\text { tardiness }\end{array}$ & $\begin{array}{l}\text { Roulette wheel } \\
\text { approach }\end{array}$ & $\begin{array}{l}\text { Job based } \\
\text { crossover(JOX) }\end{array}$ & $\begin{array}{l}\text { Operation } \\
\text { swap mutation }\end{array}$ & $\begin{array}{l}\text { Can be further } \\
\text { extended by } \\
\text { applying heuristic } \\
\text { methods separately } \\
\text { or in conjunction } \\
\text { with HGA> }\end{array}$ \\
\hline $\begin{array}{l}\text { Penalty method } \\
\text { for constraints in } \\
\text { JSSP[4] }\end{array}$ & $\begin{array}{l}\text { Minimise } \\
\text { completion time } \\
\text { for processing all } \\
\text { jobs }\end{array}$ & Clonal selection & Normal & $\begin{array}{l}\text { Inverse, } \\
\text { interchange, } \\
\text { Insert }\end{array}$ & $\begin{array}{l}\text { Proposed algorithm } \\
\text { to more practical } \\
\text { and integrated } \\
\text { problem }\end{array}$ \\
\hline $\begin{array}{l}\text { HGA \& variable } \\
\text { neighbourhood } \\
\text { descent algorithm } \\
\text { for } \\
\text { FJSSP(FMS)[5] }\end{array}$ & $\begin{array}{l}\text { 1.minimise } \\
\text { makespan } \\
\text { 2.minimise } \\
\text { maximal machine } \\
\text { workload } \\
\text { 3.minimise total } \\
\text { workload }\end{array}$ & Ranking method & $\begin{array}{l}\text { 1. Order crossover } \\
\text { for operation } \\
\text { sequence vector. } \\
\text { 2.Extended order } \\
\text { crossover and } \\
\text { uniform crossover } \\
\text { for machine } \\
\text { assignment vector }\end{array}$ & $\begin{array}{l}\text { Allele based } \\
\text { and } \\
\text { immigration } \\
\text { mutation }\end{array}$ & $\begin{array}{l}\text { Moving } 3 \text { or more } \\
\text { operation, the } \\
\text { balance between } \\
\text { genetic search and } \\
\text { total search }\end{array}$ \\
\hline Generalised & How to represent & Permutation & Generalised order & & \\
\hline
\end{tabular}




\begin{tabular}{|c|c|c|c|c|c|}
\hline $\begin{array}{l}\text { permutation } \\
\text { approach to FMS } \\
\text { with GA[6] }\end{array}$ & $\begin{array}{l}\text { the problem in the } \\
\text { algorithm }\end{array}$ & & crossover(GOX) & & \\
\hline $\begin{array}{l}\text { Evaluation of GA } \\
\text { approach for } \\
\text { scheduling } \\
\text { optimisation of } \\
\text { FMS[7] }\end{array}$ & $\begin{array}{l}\text { 1.Mininmising idle } \\
\text { time of machines } \\
\text { 2.Minimising total } \\
\text { penalty cost }\end{array}$ & $\begin{array}{l}\text { Tournament } \\
\text { selection }\end{array}$ & $\begin{array}{l}\text { Single point } \\
\text { crossover }\end{array}$ & Flipping & $\begin{array}{l}\text { Will include } \\
\text { availability \& } \\
\text { handling times of } \\
\text { load/unload } \\
\text { stations, robots, } \\
\text { AGVs. }\end{array}$ \\
\hline $\begin{array}{l}\text { FMS Scheduling } \\
\text { with knowledge } \\
\text { base GA } \\
\text { approach[8] }\end{array}$ & $\begin{array}{l}\text { Throughput \& } \\
\text { mean flow time } \\
\text { have been taken to } \\
\text { measure the } \\
\text { performance of fms }\end{array}$ & $\begin{array}{l}\text { Knowledge } \\
\text { based } \\
\text { 1.directional } \\
\text { 2.steady } \\
\text { 3.unruly }\end{array}$ & Knowledge based & $\begin{array}{l}\text { Knowledge } \\
\text { Based }\end{array}$ & $\begin{array}{l}\text { Can be stretched out } \\
\text { to various problems } \\
\text { of FMS that cover } \\
\text { the balancing or } \\
\text { allocation of } \\
\text { resources. }\end{array}$ \\
\hline $\begin{array}{l}\text { Discrete Dynamic } \\
\text { Approach[9] }\end{array}$ & $\begin{array}{l}\text { Minimising make } \\
\text { span }\end{array}$ & Random & $\begin{array}{l}\text { Sub tour chunking } \\
\text { crossover }\end{array}$ & - & $\begin{array}{l}\text { Generation of } \\
\text { global optimal } \\
\text { schedule }\end{array}$ \\
\hline $\begin{array}{l}\text { Generalised order } \\
\text { crossover[10] }\end{array}$ & $\begin{array}{l}\text { Minimising make } \\
\text { span }\end{array}$ & $\begin{array}{l}\text { Neighbourhood } \\
\text { mating and local } \\
\text { offspring } \\
\text { acceptance }\end{array}$ & $\begin{array}{l}\text { GOX i.e. } \\
\text { permutation with } \\
\text { repetitions }\end{array}$ & $\begin{array}{l}\text { Position based } \\
\text { mutation }\end{array}$ & - \\
\hline $\begin{array}{l}\text { Hybrid GA using } \\
\text { random keys[11] }\end{array}$ & $\begin{array}{l}\text { Minimising make } \\
\text { span and } \\
\text { maximising } \\
\text { tardiness }\end{array}$ & $\begin{array}{l}\text { Random and } \\
10 \% \text { direct }\end{array}$ & $\begin{array}{l}\text { Parameterized } \\
\text { uniform crossover }\end{array}$ & $\begin{array}{l}\text { Replacing } \\
\text { bottom } 20 \% \text { by } \\
\text { random } \\
\text { generation }\end{array}$ & $\begin{array}{l}\text { Breakdowns not } \\
\text { considered. }\end{array}$ \\
\hline
\end{tabular}

\section{CONCLUSION}

The ability and functions of the machines now a days have been extended on large scales, the scheduling plan of a manufacturing system might not be unique. Hence, on a practical shop floor, many feasible schedules can be found. It can be seen that Genetic Algorithm gives better result than traditional scheduling methods because of which the applicability of the GA based methodology has considerable potential application to manufacturing with further refinement in certain aspects[2] This work, and other current investigations, demonstrates that the genetic algorithm method is broad, approximate search procedure with applications in diverse problem areas.

The future scope can be spanned on the following two facets:

The transportation time and setup time are considered as constant, further work can be done using setup time and transportation time. The jobs are considered to be atomic. Further work can be done by creating schedules with various parts manufactured on different machines.

\section{REFERENCES}

[1] S.Kapoor et al Improved Solution to Job Shop Scheduling Problem with Delay constraints using Genetic Algorithm International Journal of Computer Applications (0975 8887) Volume 45- No.13, May 2012

[2] V.Singh et al GA based Scheduling of FMS using Roulette Wheel Selection Process

[3] M.Hyder et al A hybrid GA for simultaneously scheduling an FMC under multiple objectives

[4] Liang Sun et al Solving Job Shop Scheduling Problem Using Genetic Algorithm with Penalty Function

[5] Jie Gao et al A hybrid genetic and variable neighbourhood descent algorithm for flexible job shop scheduling problems
[6] Christian Bierwirth A Generalised Permutation Approach Job Shop Scheduling with Genetic Algorithm

[7] Nidhish Mathew Nidhish Evaluation of Genetic Algorithm Approach for Scheduling Optimization of Flexible Manufacturing Systems

[8] A. Prakash et al FMS scheduling with knowledge based genetic algorithm Approach

[9] Jian-Bo Yang GA-Based Discrete Dynamic Programming Approach for Scheduling in FMS Environments

[10] José Fernando Gonçalves, Jorge José de Magalhães Mendes, Maurício G.C. Resende in their paper "A Hybrid Genetic Algorithm for the Job Shop Scheduling Problem"

[11] Hameshbabu Nanvala Use of Genetic algorithm based approaches in scheduling of FMS: A review

[12] I.Sriramka Scheduling of Flexible Manufacturing System using Genetic Algorithm

[13] Kwan Woo Kim et al Network-based hybrid genetic algorithm for scheduling in FMS environments

[14] Wei He et al Scheduling flexible job shop problem subject to machine breakdown with route changing and right-shift strategies

[15] Vijay Kumar et al Scheduling of flexible manufacturing system using genetic algorithm: A heuristic approach

[16] Chinnusamy.T.R et al Flexible Manufacturing System Scheduling with Dynamic Environment

[17] Chuda Basnet et al Scheduling and Control of Flexible Manufacturing Systems: A Critical Review

[18] Pankaj Upadhyay et al Improving a Flexible Manufacturing Scheduling using Genetic Algorithm 
[19] A. Motaghedi-larijani et al Solving Flexible Job Shop Scheduling with Multi Objective Approach

[20] Farzad Khorsandi Shahrestani et al Optimization of scheduling flexible manufacturing systems by using multi-objective Genetic algorithm

[21] Jian Xiong et al robust scheduling for multi-objective flexible job-shop problems with random machine breakdowns
[22] Nasr Al-Hinai et al Robust and stable flexible job shop scheduling with random machine breakdowns using a hybrid genetic algorithm

[23] Liping Zhang et al Dynamic rescheduling in FMS that is simultaneously considering energy consumption and schedule efficiency

[24] Udhayakumar et al Task Scheduling of AVG in FMS using non-traditional optimisation techniques

[25] S.N. Sivanandam \& S.N. Deepa (2008). Principles of Soft Computing. 